\title{
Can we not work together to help family practitioners become more effective pain managers?
}

\author{
Jeffrey Fudin ${ }^{1,2,3}$ \\ Timothy J Atkinson ${ }^{4}$ \\ Mena Raouf ${ }^{4}$ \\ Michael E Schatman ${ }^{5}$ \\ 'Stratton VA Medical Center, \\ Albany, NY, USA; ${ }^{2}$ Albany College \\ of Pharmacy and Health Sciences, \\ Albany, NY, USA; ${ }^{3}$ Scientific \\ and Clinical Affairs, Remitigate \\ LLC, Delmar, NY, USA; ${ }^{4}$ VA \\ Tennessee Valley Healthcare \\ System, Murfreesboro, Nashville, \\ TN, USA; ${ }^{5}$ US Pain Foundation, \\ Bellevue, WA, USA
}

\author{
This article was published in the following Dove Press journal: \\ Journal of Pain Research \\ 13 October 2016 \\ Number of times this article has been viewed
}

Snyder et al recently published a review in American Family Physician titled, "Treating Painful Diabetic Peripheral Neuropathy: An Update", which provided an overview of pharmacologic treatment options for providers; however, some of the recommendations made by the authors were concerning. ${ }^{1}$ Recommendations that caught our attention included statements around pregabalin adjustment for renal impairment, using selective serotonin reuptake inhibitors (SSRIs) in the treatment of diabetic peripheral neuropathy (DPN), classification of tramadol, tapentadol, and oxycodone in DPN.

While highlighting the pharmacodynamic and pharmacokinetic differences between pregabalin and gabapentin, the statement regarding pregabalin having "no dosing adjustment requirement in patients with renal impairment" immediately caught our attention. That statement is not consistent with the current published literature and Food and Drug Administration guidance, and may therefore result in substantial confusion and adverse effects for patients if providers implement such misinformation into practice. Pregabalin is not metabolized hepatically and is excreted by the kidneys entirely unchanged and will, therefore, accumulate unless the dose is adjusted for renal dysfunction. The manufacturer labeling lists the maximum recommended dosing for pregabalin as $300 \mathrm{mg}$ in two to three daily divided doses for patients with a creatinine clearance $(\mathrm{CrCl})$ of $30-59 \mathrm{~mL} / \mathrm{min} ; 150 \mathrm{mg} /$ day in one to two divided doses in patients with $\mathrm{CrCl} 15-29 \mathrm{~mL} / \mathrm{min}$; and $75 \mathrm{mg} /$ day in patients with $\mathrm{CrCl}<15 \mathrm{~mL} / \mathrm{min}$. ${ }^{2}$ In patients undergoing hemodialysis, supplemental doses of pregabalin at $25-75 \mathrm{mg}$ daily after hemodialysis are recommended. Renal adjustment for pregabalin is overwhelmingly recommended in the literature, and according to rates of adverse effects and concentration-dependent toxicity, failure to adjust the dose will result in accumulation and poor treatment outcomes for patients. ${ }^{3,4}$

The review article also states, "selective serotonin reuptake inhibitors and opioids are optional third-line medications". The role of specific serotonin reuptake inhibitors (SSRIs) in treating pain associated with DPN is questionable, even to be suggested as a third-line medication. While there is a connection between mood and pain perception, SSRIs have no established mechanism or role in managing pain associated with DPN. Norepinephrine (NE) reuptake inhibition, as seen with serotonin-norepinephrine reuptake inhibitors (SNRIs) and tricyclic antidepressants, is the primary mediator of the analgesic effect. ${ }^{5}$ The review article highlighted that "Combined data from four small studies reveal an NNT [number needed to treat] of 7 for pain reduction with this
357 Delaware Avenue \#214, Delmar, NY 12054, USA

Email jeff@paindr.com 
class of medications". The supporting reference is, "SSRIs have been studied in a few trials which have demonstrated a weak analgesic effect, but the clinical relevance of these compounds is questionable", by Finnerup et al. ${ }^{6}$ There are concerns in these studies, as the methods, sample size, and results have dubious clinical relevance from which to draw conclusions about their role in DPN. The study of paroxetine for neuropathic pain involved 19 participants in an alternating crossover every 2 weeks in each arm, in which, for example, one group of six participants received a placebo for 2 weeks, followed by imipramine for 2 weeks, then paroxetine for 2 weeks. ${ }^{7}$ There are methodological weaknesses with the study, including blinding and crossover design without a washout period, as well as utilizing a drug with long elimination half-life (19 hours), of which the therapeutic effects remained during paroxetine group's test period. Similar to the paroxetine study, the citalopram study followed a 3-week crossover with a placebo in 15 participants. ${ }^{8}$ Finally, the study for escitalopram utilized a verbal pain rating scale ("complete", "good", "slight", "none", or "worse") corresponding to a score of 0-11.9 Escitalopram showed improvement by 1 point with a wide standard deviation, with the largest improvements compared to placebo falling mostly in the "none" and "slight" pain relief designations. There was no statistically significant difference in quantitative sensory testing between both the groups. None of these trials utilized a parallel group with an active comparator that was selective for NE reuptake inhibition. For these reasons, SSRIs are not currently found among recommendations for any current treatment guideline for the management of neuropathic pain. ${ }^{10-12}$ As a matter of fact, the International Association for the Study of Pain cites level A/B rating for inefficacy or discrepant results for SSRIs in neuropathic pain. ${ }^{12}$ Therefore, citing SSRIs as a third-line option may be interpreted as continuing SSRIs to treat DPN in patients who are already on SSRIs for mental health indications rather than switching to evidence-based medications such as serotonin-norepinephrine reuptake inhibitors.

Another misleading statement in Snyder et al's paper is the reference to tramadol and tapentadol as "opioid-like medications". For clarification, tramadol and tapentadol are not "opioid-like" medications but are indeed opioid agonists in the phenylpropyl amine class. ${ }^{13,14}$ Tramadol is a $\mu$-opioid receptor agonist with binding affinity 6,000 times lower than that of morphine and has a unique dual mechanism that includes inhibiting the reuptake of NE and serotonin. ${ }^{13}$ Tapentadol is a $\mu$-opioid receptor agonist with binding affinity 18 times lower than that of morphine combined with NE reuptake inhibition, resulting in synergy that improves the overall potency to five times lower than oxycodone in clinical trials. ${ }^{15}$ The benefit of tramadol and tapentadol in DPN is secondary to NE reuptake inhibition, with tapentadol carrying an Food and Drug Administration-labeled indication for DPN. ${ }^{14-16}$

The authors also state, "If opioids are used, oxycodone is commonly prescribed, but alternatives include methadone, levorphanol, and morphine". Certain opioids are presumed to be more efficacious in neuropathic pain, including those with dual mechanisms involving NE reuptake inhibition and/ or N-methyl-D-aspartate. ${ }^{17}$ Methadone and levorphanol are synthetic opioids that inhibit N-methyl-D-aspartate receptor and block the reuptake of serotonin (5HT) and NE, and NE alone, respectively. ${ }^{18}$ The usefulness of oxycodone and other single mechanism opioid agonists for neuropathic pain is questionable, particularly for long-term treatment. A Cochrane review of three studies (two for DPN and one for post-herpetic neuralgia) involving 254 participants demonstrated the absence of convincing unbiased evidence supporting the benefit of oxycodone in the treatment of DPN and post-herpetic neuralgia. ${ }^{19}$

Given the shortfalls of the review by Snyder et al, we felt compelled to write a letter to the editor of American Family Practice to reconcile any misinformation and to give the authors an opportunity to refute or explain any inaccurate statements. This is particularly important since primary care physicians treat the majority of chronic pain cases in the US, with data indicating that they feel ill-prepared to do so. ${ }^{20,21}$ However, upon reviewing their submission policies, we learned that, "The first/corresponding author must be an experienced physician”. This came as a shock to all of us, as various ambiguities were glaring. Disallowing interdisciplinary participation, especially as an editorial, is an erstwhile policy in our minds and counterintuitive to the spirit of interdisciplinary medicine, which is an essential component of pain therapeutics and one of the major reasons for the opioid epidemic on our hands. An email was sent to the editors of American Family Physician explaining our concerns with a request to reconsider their policy and provide a fair peer review of our letter. We did not even receive an acknowledgement of the email after two attempts.

Ethically, we struggle with the complacence of the journal at several levels. While none of us is an MD or DO, we are well-published and have contributed as lead authors ubiquitously; we are pain clinicians, researchers, and educators, with considerable experience in training primary care physicians in pain management. We appreciate the rich 
body of data indicating that interdisciplinarity results in more effective pain management. ${ }^{22}$ By rejecting our letter, American Family Practice deprived its readership of access to information from sources other than physicians who are critical to the best practice of pain medicine. Family physicians often feel isolated in their practices. ${ }^{23}$ Therefore, excluding nonphysicians' input serves to perpetuate their sequestered, and not particularly effective, approaches to pain management. Finally, it appears that the editor of American Family Practice may have potentially attempted to obfuscate the weaknesses of the review that the journal published. If that indeed is the case, it leaves their readership with inaccurate information - and the potential to practice pain management less effectively than would be optimal. If it is not, we would welcome an editorial from their editorial staff that clarifies their intent.

In conclusion, our hope is that the editors of American Family Practice will not only be more diligent regarding the quality of the science published, but that journal editors and their leadership examine their collective moral compass in regard to draconian policies and potentially ensconcing the truth - as failure to do so will certainly not help family physicians gain greater competence in their efforts to manage pain, mitigate risk, and reign in a presumed opioid epidemic.

\section{Disclosure}

Dr. Fudin disclosed the following: DepoMed (Advisory Board, Speakers Bureau), Endo (Consultant, Speakers Bureau), Kaléo (Speakers Bureau, Advisory Board), Kashiv Pharma (Advisory Board), KemPharm (Consultant), Pernix Therapeutics (Speaker), Remitigate, LLC (Owner), and Scilex Pharmaceuticals (Consultant).

This article is the sole work of the authors, and stated opinions/assertions do not reflect the opinion of employers, employee affiliates, and/or pharmaceutical companies listed. It was not prepared as part of the authors' duty as federal employees. The authors report no other conflicts of interest in this work.

\section{References}

1. Snyder MJ, Gibbs LM, Lindsay TJ. Treating painful diabetic peripheral neuropathy: an update. Am Fam Physician. 2016;94(3):227-234.

2. Lyrica $^{\circledR}$ (pregabalin) [package insert]. New York, NY: Pfizer; 2016.
3. Randinitis EJ, Posvar EL, Alvey CW, Sedman AJ, Cook JA, Bockbrader HN. Pharmacokinetics of pregabalin in subjects with various degrees of renal function. J Clin Pharmacol. 2003;43(3):277-283.

4. Yoo L, Matalon D, Hoffman RS, Goldfarb DS. Treatment of pregabalin toxicity by haemodialysis in a patient with kidney failure. Am J Kidney Dis. 2009;54(6):1127-1130.

5. Max MB, Lynch SA, Muir K, Shoaf SE, Smoller B, Dubner R. Effects of desipramine, amitriptyline, and fluoxetine on pain in diabetic neuropathy. $N$ Engl J Med. 1992;326(19):1250-1256.

6. Finnerup NB, Sindrup SH, Jensen TS. The evidence for pharmacological treatment of neuropathic pain. Pain. 2010;150(3):573-581.

7. Sindrup SH, Gram LF, Brosen K, Eshoj O, Mogensen EF. The selective serotonin reuptake inhibitor paroxetine is effective in the treatment of diabetic neuropathy symptoms. Pain. 1990;42(2):135-144.

8. Sindrup SH, Bjerre U, Dejgaard A, Brosen K, Aaes JT, Gram LF. The selective serotonin reuptake inhibitor citalopram relieves the symptoms of diabetic neuropathy. Clin Pharmacol Ther. 1992;52(5):547-552.

9. Otto M, Bach FW, Jensen TS, Brosen K, Sindrup SH. Escitalopram in painful polyneuropathy: a randomized, placebo-controlled, cross-over trial. Pain. 2008;139(2):275-283.

10. Bril V, England J, Franklin GM, et al. Evidence-based guideline: treatment of painful diabetic neuropathy: report of the American Academy of Neurology, the American Association of Neuromuscular and Electrodiagnostic Medicine, and the American Academy of Physical Medicine and Rehabilitation. Neurology. 2011;76(20):1758-1765.

11. Tesfaye S, Boulton AJM, Dyck PJ, et al. Diabetic neuropathies: update on definitions, diagnostic criteria, estimation of severity, and treatments. Diabetes Care. 2010;33(10):2285-2293.

12. International Association for the Study of Pain. Pharmacological management of neuropathic pain. Pain. 2010;18(9):1-7.

13. Raffa RB, Buschmann H, Christoph T, et al. Mechanistic and functional differentiation of tapentadol and tramadol. Expert Opin Pharmacother. 2012;13(10):1437-1449.

14. Codd E, Shank RP, Schupsky JJ, Raffa RB. Serotonin and norepinephrine uptake inhibiting activity of central acting analgesics. J Pharmacol Exp Ther. 1995;274(3):1263-1270.

15. Hartrick CT, Rozek RJ. Tapentadol in pain management: a $\mu$-opioid receptor agonist and noradrenaline reuptake inhibitor. CNS Drugs. 2011;25(5):359-370.

16. Nucynta ${ }^{\circledR}$ (tapentadol immediate release oral tablets) package insert. Titusville, NJ: Janssen Pharmaceuticals, Inc.; 2013.

17. Zorn KE, Fudin J. Treatment of neuropathic pain: the role of unique opioid agents. Pract Pain Manag. 2011;11(4):26-33.

18. Pham T, Fudin J, Raffa R. Is levorphanol a better opioid than methadone. Pain Med. 2015;16(9):1673-1679.

19. Gaskell H, Moore RA, Derry S, Stannard C. Oxycodone for neuropathic pain and fibromyalgia in adults. Cochrane Database Syst Rev. 2014;(6):CD010692.

20. Breuer B, Cruciani R, Portenoy RK. Pain management by primary care physicians, pain physicians, chiropractors, and acupuncturists: a national survey. South Med J. 2010;103(8):738-747.

21. Vijayaraghavan M, Penko, J, Guzman D, Miaskowski C, Kushel MB. Primary care providers' view on chronic pain management among highrisk patients in safety net settings. Pain Med. 2012;13(9):1141-1148.

22. Gatchel RJ, McGeary DD, McGeary CA, Lippe B. Interdisciplinary chronic pain management: past, present, and future. Am Psychol. 2014;69(2):119-130.

23. Roy A, Breton M, Loslier J. Providing continuity of care to a specific population: attracting new family physicians. Can Fam Physician. 2016;62(5):e256-e262. 
Dove Medical Press encourages responsible, free and frank academic debate. The content of the Journal of Pain Research 'Editorial' section does not necessarily represent the views of Dove Medical Press, its officers, agents, employees, related entities or the Journal of Pain Research editors. While all reasonable steps have been taken to confirm the content of each Editorial, Dove Medical Press accepts no liability in respect of the content of any Editorial, nor is it responsible for the content and accuracy of any Editorial.

Journal of Pain Research

Publish your work in this journal

The Journal of Pain Research is an international, peer reviewed, open access, online journal that welcomes laboratory and clinical findings in the fields of pain research and the prevention and management of pain. Original research, reviews, symposium reports, hypothesis formation and commentaries are all considered for publication. 